\title{
SANEAMENTO BÁSICO: DIREITO ASSEGURADO PELA CONSTITUIÇÃO FEDERAL
}

\author{
Célia Regina Ferrari Faganello ${ }^{1}$ \\ Olimpio Muniz Fiuza Neto ${ }^{2}$
}

\section{RESUMO}

Objetivo do estudo: Analisar se o direito ao saneamento básico era, de fato, a ssegura do para a população de Porto Seguro assim como é prezado na Constituição da República Federativa do Brasil, a partir das percepções da população. Além disso, buscamos entrecruzar como referencial teórico os pensamentos de Patrícia Borja e a realidade do saneamento vivenciada pelo público em Porto Seguro. Metodologia: O método utilizado foi o quantitativo. Assim sendo, foram aplicados questionários para a população em Unidades Básicas de Saúde de três diferentes bairros da cidade. Em seguida foi feita uma análise quantitativa dos resultados. Relevância: O tema está conexo com a intrínseca relação entre a efetiva prestação dos serviços de saneamento básico e a qualidade de vida da população. Principais resultados: Ficou evidenciada a enorme insatisfação popular com os serviços de sa nea mento básico oferta dos na cidade de Porto Seguro. Apesar das legislações assegurarem a plena eficácia do serviço, na prática não é o que a população percebe, já que conforme os resultados obtidos $83 \%$ dos entrevistados discordavam da plena eficá cia do serviço. Outro fator a nalisa do foi a percepção de que a maioria não sabia o engloba va os serviços de sanea mento básico. Contribuições teóricas: O presente trabalho traz como contribuição um implemento na relevância a tribuída a os direitos socia is hodierna mente, mostrando que os mesmos se a na lisa dos sob um viés holístico influenciam diretamente na qualidade de vida da população e concomitantemente na manutenção de um meio a mbiente saudávele equilibrado.

Palavras-Chave: Saneamento Básico; Efetividade; Povo; Unidades Básicas de Saúde, Qualidade de vida.

Submetido em: 10/02/2021

Aprovado em: 01/06/2021

DOI: $\underline{\text { https://doi.org/10.37497/revcampojur.v9i1.673 }}$

\begin{abstract}
${ }^{1}$ Pós Doutorado em Direito Ambiental pela Universidade de Toulon (França). Professora associada, nível II, do Instituto de Humanidades, Artes e Ciências Sosígenes Costa, da Universidade Federal do Sul da Bahia (UFSB), Bahia (Brasil). E-mail: crfagane@gmail.com. ORCID: https://orcid.org/0000-0003-3227-1916
\end{abstract}

${ }^{2}$ Bacharel em Humanidades, Universidade Federal do Sul da Bahia. Bahia- BA, Brasil. Email: olimpiofiuza@hotmail.com ORCID: https://orcid.org/0000-0001-5153-3868

\section{Campo Jurídico|Barreiras (BA) | v.9 |e673| p.01-21 |Janeiro-Junho|2021}




\title{
SANITATION: RIGHT GUARANTEED BY THE FEDERAL CONSTITUTION
}

\begin{abstract}
Objective of the study: To analyze whether the right to basic sanitation was, in fact, guaranteed to the population of Porto Seguro, as established in the Constitution of the Federative Republic of Brazil, based on the population's perceptions. In addition, we sought to intertwine as a theoretical framework the thoughts of Patrícia Borja and the rea lity of sanitation experienced by the public in Porto Seguro. Methodology: The method used was quantitative. Therefore, questionnaires were applied to the population in Basic Health Units in three different districts of the city. Then a quantitative analysis of the results was performed. Relevance: The theme is connected with the intrinsic relationship between the effective provision of basic sanitation services and the population's qua lity of life. Main results: The huge popular dissatisfaction with the basic sanitation services offered in the city of Porto Seguro was evident. Despite the legislation ensuring the full effectiveness of the service, in practice this is not what the popula tion perceives, as according to the results obtained, $83 \%$ of respondents disa greed with the full effectiveness of the service. Another factor analyzed was the perception that the majority did not know what the basic sanitation services encompassed. Theoretical contributions: This work brings as a contribution an implement in the relevance attributed to social rights nowadays, showing that if analyzed under a holistic perspective, they directly influence the quality of life of the population and concomitantly maintain a healthy and balanced environment.
\end{abstract}

Keywords: Basic Sanitation; Effectiveness; People; Basic Health Units; Quality of life.

\section{INTRODUÇÃO}

Na Constituição da República Federativa do Brasil de 1988 em seu art. 23 é trazido como competência comum a União, Estados, Municípios e o Distrito Federal a promoção de melhorias no tocante as condições mínimas de Saneamento Básico. Contudo, apesar de se tratar de um assunto de extrema complexidade, pois vai além da saúde pública perpassando também pela dignidade do ser humano, este muitas vezes é tido como algo que unicamente estaria relacionado com o abastecimento de água e esgotamento sanitário. Sem embargo, como pode ser constatado na lei 11.445/07 onde são estabelecidas as diretrizes nacionais para o saneamento básico, este serviço engloba além do abastecimento de água potável o esgotamento sanitário, pois também abrange a limpeza urbana, manejo de resíduos sólidos, drenagem e gestão das águas pluviais e por fim a limpeza e concomitantemente fiscalização preventiva das redes urbanas.

Diante da complexidade e relevância do tema, é possível verificar que este envolve não somente a qualidade de vida e saúde do povo, mas também contribui diretamente na redução das desigualdades e promoção de uma vida digna para a população. Destarte, mesmo com toda essa expressividade do assunto, o Estado da Bahia apenas possui o total de 57,4\% das pessoas em domicílios com acesso à rede coletora ou

Campo Jurídico|Barreiras (BA) | v.9 |e673| p.01-21 |Janeiro-Junho|2021 
pluvial. Esse índice estadual supera o do Nordeste que é de 47,2\%, porém é inferior ao do país $68,3 \%$. Já em relação ao abastecimento de água por rede geral é apenas em torno de 84,5\%, de acordo com os dados divulgados em 2019 da Pesquisa Nacional por Amostra de Domicílios Contínua - Características dos Moradores e dos Domicílios, divulgada pelo IBGE.

A Lei 11.445/07 também prevê a obrigatoriedade de elaboração de um plano de saneamento básico para oferecer ao homem uma boa qualidade de vida. Assim, de acordo com esta Lei saneamento básico é:

\begin{abstract}
Um conjunto de serviços de abastecimento público de água potável; coleta, tratamento e disposição final adequada dos esgotos sanitários; drenagem e manejo das águas pluviais urbanas, a lém da limpeza urbana e o manejo dos resíduos sólidos. (BRASIL, 2010,p.1)
\end{abstract}

Em Porto Seguro a situação já é diferente porque foi firmado no município em 02 de outubro de 2017 o Plano Municipal de Gestão Integrada de Resíduos Sólidos (PMGIRS), instrumento que consolida as diretrizes, estratégias e metas para a gestão ambientalmente responsável dos resíduos no município no horizonte de 20 anos, em cumprimento à Lei 12.305/2010 que institui a Política Nacional de Resíduos Sólidos, PNRS.

Destarte, mesmo com a elaboração do Plano Municipal a situação do Saneamento Básico no município apesar de estar melhor que a média nacional ainda preocupa de acordo com os dados coletados em 2013 pelo Sistema de Informação da Atenção Básica (SIAB) do Ministério da Saúde. Conforme as informações disponibilizadas em 2016 pela Agência Reguladora de Saneamento Básico do Estado da Bahia (AGERSA) a melhor situação apresentada no município é no que diz respeito ao percentual de famílias conectadas a rede pública de esgoto que na época era de $84,25 \%$, enquanto a média nacional estava em $65,9 \%$. A coleta de lixo no domicílio também não atingia totalmente os domicílios sendo que ficou em torno de $95,78 \%$ e a nacional em torno de $91,4 \%$. A pior situação está no tocante ao percentual de domicílios com água canalizada pois na época a média nacional era de $97 \%$ já na cidade ficou em torno de apenas 77,44\% dos imóveis, fazendo com que a população utilize meios alternativos e por muitas vezes ilegais de abastecimento que podem ser prejudiciais à saúde como o abastecimento por poços artesianos e cisternas a céu aberto.

Campo Jurídico|Barreiras (BA) | v.9 |e673| p.01-21 |Janeiro-Junho|2021 
Desta forma, fica claro que o saneamento básico está intrinsecamente ligado a uma questão de saúde pública, a começar pelo primeiro aporte trazido na lei no ${ }^{\circ} 11.445 / 2007$ que o referente a água, matéria essa que de acordo com o médico cancerologista Dráuzio Varella, a sua falta pode acarretar consequências terríveis para o organismo humano como tonturas, maior predisposição para outras doenças e até mesmo levar à morte.

Outro aspecto que relaciona intimamente o tema à saúde pública é a problemática de esgotamento sanitário, a exemplo podemos verificar nos indicadores de dados básicos de 2015, divulgados no DATASUS do Ministério da Saúde onde um aumento de $78 \%$ da rede de esgoto diminuiu $91 \%$ da taxa de internação por doenças diarreicas na cidade de Campo Grande.

A escolha desse tema se justificou, academicamente, por uma pretensão de colaborar com informações que pudessem ajudar na situação do saneamento básico no município de Porto Seguro - BA, alertando a população sobre a complexidade do tema bem como explanando acerca das legislações vigentes e as garantias que são dever do Poder Público garantir. Outro exemplo de validação e relevância do tema pode ser visto na Constituição do Estado da Bahia em seu artigo 227, no qual apresenta uma visão holística acerca dos serviços de saneamento básico:

Compreende abastecimento de á gua, coleta e disposição a dequa da dos esgotos e do lixo, drena gem urbana de á guas pluvia is, con trole de vetores transmissores de doenças e atividades relevantes para promoção da qualidade de vida. (BAHIA,1947, p.6).

Assim, mesmo diante de todo esse arcabouço legislativo como forma de assegurar uma melhor qualidade de vida para a população, ficou evidente que é de extrema importância analisar também as intrínsecas relações entre os serviços de saneamento e as reais condições de vida da população. Isto posto, se fazia necessário constatar se realmente as legislações estavam sendo cumpridas como é prezado na Constituição Federal, sendo dever dos entes federados promover os programas de construção de moradias e a melhoria das condições habitacionais e de saneamento básico (BRASIL, Constituição,1988). 


\section{PROBLEMA}

O problema precípuo desta pesquisa foi baseado na investigação acerca da percepção da população de Porto Seguro sobre o direito ao saneamento básico. Este direito estava de fato garantido e não apenas mencionado na Legislação?

\section{HIPÓTESE}

Apesar do amparo legislativo expresso no artigo no 227 na Constituição do Estado da Bahia, bem como no que rege o artigo n 23 da Constituição Federal o qual dispõe como dever tanto da União como dos Estados, Municípios e Distrito Federal a instituição de programas de melhorias nos serviços de saneamento básico, a hipótese desta pesquisa foi pautada na suposição de que o direito ao Saneamento básico não estava garantido de forma efetiva à população de Porto Seguro, ficando apenas no arcabouço teórico das legislações vigentes.

\section{OBJETIVOS}

\section{Objetivo Geral}

O intuito colimado desta pesquisa foi analisar se o direito ao saneamento básico de fato era assegurado para a população de Porto Seguro, assim como é prezado na Constituição da República Federativa do Brasil.

\section{Objetivos Específicos}

- Perscrutar a opinião da população de Porto Seguro acerca do Saneamento Básico no Município;

- Verificar o alcance dos serviços de saneamento básico prestados em três unidades de Porto Seguro;

- Analisar a efetivação da legislação acerca do saneamento básico para população de Porto Seguro.

\section{SEÇÃO METODOLÓGICA}

O métod o utilizado foi o quantitativo. Assim sendo, foram aplicados questionários para a população em Unidades Básicas de Saúde de três diferentes bairros da cidade. Em 
seguida foi feita uma análise quantitativa dos dados para a elaboração dos gráficos e alcance dos resultados.

\section{METODOLOGIA}

A metodologia utilizada nesta pesquisa foi a do tipo quantitativa, que segundo Manzato Santos (2012, p. 07) é utilizada quando "se quer medir opiniões, reações, sensações, hábitos e atitudes etc. de um universo (público-alvo) através de uma amostra que o represente de forma estatisticamente comprovada". A obtenção dos dados ocorreu através de um questionário fechado (anexo I) que foi respondido pelo próprio sujeito da pesquisa. A amostragem foi limitada em 30 participantes, pois segundo Morse (1994) e Creswell (1998) "uma quantidade consensual seria de, pelo menos, 20 a 30 entrevistas para qualquer tipo investigação qualitativa" (apud Minayo 2017, p. 6).

Para Chaer, Diniz e Ribeiro (2011) o questionário tem como objetivo sanar dúvidas sobre o tema, contudo, é importante que ele não fique extenso ao ponto de desmotivar a colaboração do participante. Desse modo, foi elaborado um questionário com dez perguntas que abordaram o que as pessoas achavam sobre o saneamento básico em Porto Seguro; se elas sabiam quais eram os serviços que faziam parte do saneamento e se eles sabiam dos direitos que lhes eram assegurados pela Constituição Federal, bem como as demais legislações vigentes acerca do Saneamento Básico.

Em seguida, eles foram disponibilizados para os usuários que estivam presentes nas unidades básicas de saúde no momento da visita, estes responderam ao questionário nas recepções dos postos de saúde, por fim os questionários foram recolhidos para serem posteriormente analisados.

Apesar do público que frequenta as Unidades Básicas de Saúde ser bastante variado, o público que foi colimado para responder este questionário foi de dez participantes por Unidade, sendo que como critério de exclusão foram estabelecidas as seguintes regras: não participariam os relativamente e absolutamente incapazes, os quais de acordo com legislação que estabelece o Código Civil Brasileiro a lei nº 10.406/2002, 
o qual dispõe em seu artigo $3^{\text {o: }}$ "São absolutamente incapazes de exercer pessoalmente os atos da vida civil os menores de dezesseis anos."

Já os são relativamente incapazes são: os maiores de dezesseis e menores de dezoito anos, os ébrios habituais, os viciados em tóxico, aqueles que por causa transitória ou permanente não puderem exprimir sua vontade e os pródigos.

Como já fora previamente verificado a intrínseca relação do tema com a saúde pública foram escolhidos os locais para a coleta de dados as unidades de saúde da família de Porto Seguro. Esses locais, puderam proporcionar uma visão holística acerca da percepção da população sobre a real situação do saneamento básico na cidade, já que em cada distrito sanitário a realidade pode se tornar diferente pela visibilidade turística da região. Tal diferenciação segundo a pesquisa "Duas Porto Seguro" da arquiteta e educadora Cristina Pereira de Araújo tem início desde a década de 70 com a organização da ocupação turística da cidade onde a especulação imobiliária dos investidores fez com que a área do centro passasse por mudanças de uso como a criação de pousadas no lugar das residências convencionais, já na orla norte passou a abrigar grandes hotéis de luxo ; e por fim, a população local e migrante passou a morar nas áreas periféricas da cidade .No caso de Porto Seguro, o município é dividido em quatro distritos sanitários: Centro, Litoral Sul, Frei Calixto e Rural e possui quarenta e três unidades, conforme os dados disponibilizados pela Secretaria Municipal de Saúde.

Dentre as possibilidades de escolha optou-se por três unidades localizadas nas zonas três zonas turísticas apontadas na pesquisa de Cristina Pereira. Essas estão localizadas em dois distritos sanitários, os do centro e do Frei Calixto. Estes são localizadas nos bairros do centro a denominada de Dr. Heraldo Lima I, na orla intitulada por Orla Norte e por fim a unidade Arlinda Almeida, a qual é localizada no bairro das Casas Novas no Frei Calixto. Deste modo os critérios de inclusão foram: a aceitação das condições estabelecidas nos termos de consentimento e livre esclarecimento e que fosse morador de uma das três áreas previamente dissertadas.

A aplicação do questionário foi realizada no decorrer do mês de outubro de 2020. Na ocasião não foi dada preferência ao gênero, raça, cor ou nível de escolaridade, ou seja, os únicos critérios de exclusão eram os já previamente abordados. Não foi exigido 
também que fosse preenchido o nome, apenas a assinatura e a região da cidade onde resida.

Outro fator preponderante na escolha dessas unidades para a realização das entrevistas foi que de acordo com as diretrizes colimadas pelo Ministério do Planejamento a população visada destes órgãos é a que realmente vive nos bairros em que são instaladas:

A Unidade Básica de Saúde (UBS) é o contato preferencial dos usuários, a principal porta de entrada e centro de comunicação com toda a Rede de Atenção à Saúde. É instalada perto de onde as pessoas moram, traba lham, estudam e vivem e, com isso, desempenha um papel central na garantia de acesso à população a uma a tenção à saúde de qualidade (BRASIL, S/D).

A partir da obtenção dos dados ocorreu uma seleção, que visa à exatidão das informações, em seguida foi feita uma categorização, onde os dados foram agrupados em categorias para facilitar a tabulação dos resultados obtidos. Através da tabulação, foi possível realizar a verificação da visão da população acerca dos serviços prestados na cidade separando por um viés setorial e um panorama regionalizado.

Em seguida foram feitos gráficos que serviram para verificar o nível da percepção de qualidade da população de Porto Seguro no tocante aos serviços de saneamento básico prestados.

Os resultados encontrad os foram publicados independentemente do resultado ao final da pesquisa. Assim, diante dos fatos apresentados essa pesquisa teve o objetivo de não só perscrutar a população local, mas também mostrar os diversos pontos de vista dos moradores de cada região, para saber se a legislação vigente está sendo efetivada.

\section{FUNDAMENTAÇÃO TEÓRICA}

\section{SANEAMENTO BÁSICO: CONTEXTUALIZAÇÃO NO ESTADO, PARTICIPAÇÃO POPULAR E IMPORTÂNCIA DOS SERVIÇOS}

O serviço de saneamento básico no Brasil, apesar de ser reconhecido como um direito humano essencial, está longe de ser alcançado. A incompatibilidade entre o nível de riqueza do país e o déficit para o acesso aos requisitos mínimos, conferem ao Estado brasileiro políticas, programas e ações que possibilitem o acesso e a garantia da universalização desse serviço público (BORJA, CUNHA, 2018).

A contextualização governamental do saneamento no Brasil foi iniciada com o Plano Nacional de Saneamento (PLANASA), este projeto foi criado em 1971 pelo então 
Banco Nacional de Habitação (BNH). Contudo, para Borja (2014) apesar de ser um grande passo já que levaria as atenções para o real planejamento do setor, este apenas focou na parte do esgotamento sanitário e abastecimento de água potável, deixando de fora os aspectos do manejo dos resíduos sólidos e drenagem de águas pluviais. Tal abordagem vigorou até 1986 quando houve o esvaziamento do plano, justamente pela falência do BNH em 1986, banco este que era o seu maior incentivador financeiro. A partir daí passa a ser construído um novo conceito que vai ser incorporado na nova Lei Nacional de Saneamento Básico a de $n^{\circ}$ 11.445, promulgada em 2007, após intensos processos de negociação entre diversos atores sociais (BORJA, 2014, p.2).

De acordo com Follador et.al. (2015) o saneamento básico é definido como o conjunto de serviços e ações que objetivam alcançar níveis crescentes de salubridade ambiental, nas condições que maximizem a promoção e a melhoria das condições de vida nos meios urbano e rural. A lei supracitada descreve que o saneamento básico abrange os serviços: de infraestrutura e instalações operacionais de abastecimento de água, esgotamento sanitário, limpeza urbana, drenagem urbana, manejos de resíduos sólidos e de águas pluviais.

Na Bahia após o término do PLANASA foi iniciado nos anos 90 o projeto chamado de Bahia Azul, o qual tinha o intuito colimado de "mudar o quadro de degradação ambiental" na Baía de Todos os Santos (BTS), bem como dos centros urbanos do seu entorno (BAHIA, 1995). Para o prosseguimento do projeto foram pensadas na parceria com Instituições Financeiras Internacionais para contribuir com o patrimônio investido, já que inicialmente era previsto um investimento externo em torno de US\$415 milhões, segundo a estimativa do Programa Ambiental da Baía de todos os Santos (BTS). Apesar dos voluptuosos investimentos na cidade, o projeto de saneamento implementado em Salvador ficou aquém do esperado:

\footnotetext{
Embora o Programa Bahia Azul (PBA) tenha realizado obras no sistema de saneamento básico na cidade de Salvador, essas intervenções não foram suficientes para melhorar a qualidade da água fornecida para população (BORJA, 2006, p.8).
}

Corroborou com a ineficácia do plano o professor titular em saneamento, do Departamento de Engenharia Ambiental da Universidade Federal da Bahia (UFBA), Luiz Roberto Santos Moraes. O professor, concedeu entrevista em março de 2007 para o site "A tarde online", onde abordou que apesar das melhorias que ocorreram na cidade, o intuito inicial do plano não foi atingido. Para Moraes (2006) o projeto também não teve 
sua eficácia contemplada já que apesar dos 300 milhões de dólares investidos na cidade, as melhorias ocorridas ficaram em descompasso com a meta colimada. A cobertura da rede de esgoto em Salvador era de $26 \%$ em 1995 e a meta para o final do plano em 2000 era para se chegar em $80 \%$, destarte apenas $68 \%$ da cobertura foi atingida. Para o pesquisador um dos principais motivos da não concretização foi a falta de sinergia com os demais entes responsáveis.

A participação popular é de suma relevância para o oferecimento dos serviços de saneamento a contento das reais necessidades do povo, como pode ser observado na ineficácia do plano Bahia Azul. Conforme Teixeira (2018, p.2) os componentes do saneamento básico se oferecidos de forma precária podem afetar de forma relevante e permanente à saúde da população. Segund o estudos realizados por Follador et. al. (2015) o tratamento adequado de água e esgoto colaboram para a melhoria da saúde populacional, evitand o assim doenças como diarreia, dengue, cólera, esquistossomose e leptospirose. Ainda segundo o autor, a falta de saneamento básico é a principal responsável pela morte por diarreia de crianças menores de 5 anos no Brasil, sendo que em geral, os índices de mortalidade infantil caem $21 \%$ quando são feitos investimentos em saneamento básico Follador et. al. (2015, p.26).

Assim, com o intuito de dar uma maior abrangência a definição do tema, foi acrescentado pela Fundação Nacional de Saúde (Funasa) o conceito de controle de vetores de doenças na determinação do significado de Saneamento Básico (Teixeira, 2018, p.3).

Diante do exposto, fica clara a transcendência do tema da simples disposição do esgoto e do abastecimento de água potável.

Destarte, podemos ver uma contrapartida na pesquisa "Percepções sobre Saneamento Básico”, desenvolvida pelo Instituto Trata Brasil em 2012, na qual foram feitas entrevistas com a população e percebido que apesar da complexidade e importância do assunto, $30 \%$ dos entrevistados sequer sabiam o que era saneamento básico e $29 \%$ não tinha conhecimento sobre como funcionava o esgotamento sanitário.

Não obstante, mesmo diante da realidade de desconhecimento acerca dos serviços Governamentais prestados e da extrema importância da participação popular no tema, quando foi questionado acerca da cobrança perante ao Poder Público pelas atividades prestadas, apenas 25\% das pessoas afirmaram que já buscaram garantir seus direitos quando o tema é saneamento básico. É importe ressaltar que é de responsabilidade do 
poder público orientar quanto aos cuidados necessários com relação à saúde, fiscalizar o cumprimento das determinações e, por fim, manter a população informada (SOARES, et. al. 2020). De acordo com o autor supracitado uma das responsabilidades das empresas prestadoras de serviços de abastecimento de água e de esgotamento sanitário é realizar a etapa de desinfecção da água para abastecimento público, conforme diretrizes estabelecidas na PRT MS 05/2017 para os sistemas de tratamento e das soluções alternativas de abastecimento.

A realidade do saneamento em Porto Seguro já se contrapõe ao primor que oferece aos turistas que visitam a cidade, pois conforme os dados disponibilizad os pela Prefeitura a cidade de apenas 140 mil habitantes, recebe mais de 1 milhão de turistas anualmente. Contudo, apesar de dessa enorme visibilidade turística, os serviços públicos não são prestados a contento. Conforme as informações disponibilizadas em 2016 pela Agência Reguladora de Saneamento Básico do Estado da Bahia (AGERSA), a cobertura de água dos imóveis em Porto Seguro estava em torno de apenas 77, 44\%, já no tocante a cobertura de esgoto estava disponível para somente $84,25 \%$ da população.

Já no tocante ao sistema de drenagem de águas pluviais, o planejamento e a implantação do sistema ficam a cargo da Secretaria Municipal de Obras, e a operação e manutenção do sistema de águas pluviais são realizadas pela Secretaria de Trânsito e Serviços Públicos. Em estudo realizado com colaboração da Secretaria de Desenvolvimento Urbano (SEDUR) em 2011, foram apontadas algumas fragilidades no sistema de infraestrutura e drenagem urbana, pois este recebeu uma nota de 2.9 no índice de fragilidade, ou seja, para os parâmetros utilizados nos estudos o sistema de drenagem de Porto Seguro requer atenção e mais investimentos.

No que tange acerca da coleta de lixo fica em torno de aproximadamente $97 \%$ do total da cidade uma pequena parcela (3\%) incinera o lixo que produzem casa, segundo os dados fornecidos pelo Governo Municipal e divulgados em 2018. Diante do exposto, infere-se que a poluição contribui de forma acentuada na disseminação de doenças, desta forma os gastos com os serviços de saneamento devem ser vistos de forma holística, pois quando se investe em um saneamento de qualidade, concomitantemente haverá uma diminuição nas despesas com a saúde do povo, inclusive, segundo Follador et. al.(2015) a promoção do saneamento básico implica na diminuição da procura de hospitais e transmissão de doenças.

\section{Campo Jurídico|Barreiras (BA)| v.9 |e673| p.01-21 |Janeiro-Junho|2021}


Neste sentindo para Marchi (2015), garantir uma boa gestão em saneamento é questão de sobrevivência para a sustentabilidade do meio ambiente e social e forma a reduzir custos. Canela Junior (2011), acredita também que o Estado tem o dever de gerir seus recursos de forma que um dos direitos assegurados pela Constituição Federal que é a dignidade da pessoa humana não seja afetado, sendo obrigação do Governo à promoção de formas para a obtenção dos meios necessários para implementação do mínimo existencial:

Se o Estado social constata a insuficiência de receita para a consecução de seus fins, não paralisa sua ação, mas inicia a programação no tempo dos elementos de arreca dação e otimiza os ga stos futuros mediante a aplicação do princípio da proporcionalidade na distribuição dos recursos (CANELA JUNIOR, 2011, p. 232).

Assim, diante do exposto fica claro que os investimentos em saneamento básico devem ser ponderados a partir de uma visão ampla já que a sua eficácia final termina por influenciar em outros departamentos. No entanto, na ingerência da alocação dessas finanças é de suma relevância também a participação popular, pois como pode ser visto no plano Bahia Azul apesar de terem sido aplicados vultuosos investimentos, o resultado final ficou aquém do esperado, contribuindo assim para um maior distanciamento do atingimento do então almejado mínimo existencial.

\section{QUESTIONÁRIO}

\section{1) Onde você mora em Porto Seguro?}
A) Centro (10)
B) Casas Novas (10)
C) Orla (10)

\section{2) Saneamento Básico para você engloba?}

\section{A) Água e Esgoto; (1 ORLA, 3 BAIRROS, 3 CENTRO)}

5 B) Água, Esgoto, Drenagem de Águas pluviais, Limpeza Urbana e Manejo de Resíduos Sólidos, Drenagem e Manejo das Águas Pluviais; (2 ORLA 1 BAIRROS, 2 CENTRO)

18 C) Água, Esgoto, Drenagem de Águas pluviais, Limpeza Urbana e Manejo de Resíduos Sólidos, Drenagem e Manejo das Águas Pluviais, Limpeza do Ar da cidade; (7 ORLA 6 BAIRROS, 5 CENTRO)

\section{3) Acredita que os serviços de saneamento básico são:}


27 A) Muito Importantes (10 ORLA , 9 BAIRROS , 8 CENTRO)

3 B) Importantes (1 BAIRROS , 2 CENTRO)

C) Inúteis

4) O Saneamento Básico no seu bairro é eficaz em Porto Seguro?

5 A) $\operatorname{Sim}$ (2 ORLA 1 BAIRROS, 2 CENTRO)

9 B) Não (3 ORLA 3 BAIRROS, 3 CENTRO)

16 C) Em partes (5 ORLA 6 BAIRROS, 5 CENTRO)

5) No período chuvoso, as ruas próximas de sua residência são alagadas?

15 A) Sim (6 ORLA 4 BAIRROS, 5 CENTRO)

14 B) Não (4 ORLA 5 BAIRROS, 5 CENTRO)

1 C) Não sabe dizer (1 BAIRROS)

6) Sobre a limpeza pública, você verifica a passagem de caminhões recolhendo o lixo em seu bairro?

14 A) Sim (6 ORLA, 2 BAIRROS, 6 CENTRO)

4 B) Não (3 BAIRROS, 1 CENTRO)

12 C) Poucas Vezes (4 ORLA, 5 BAIRROS, 3 CENTRO)

7) Qual sua opinião pelos serviços prestados pela Embasa na Cidade?

2 A) Ótimos (2 CENTRO)

20 B) Bons (7 ORLA, 7 BAIRROS, 6 CENTRO)

8 C) Ruins (3 ORLA 3 BAIRROS, 2 CENTRO)

8) Pensando na administração Municipal dos últimos 8 anos, o (a) $\mathrm{Sr}$ (a) diria que os serviços na área de saneamento do seu bairro:

6 A) Melhoraram Muito (2 ORLA, 2 BAIRROS, 2 CENTRO)

17 B) Praticamente não mudaram (5 ORLA, 6 BAIRROS, 6 CENTRO)

7 C) Pioraram (3 ORLA, 2 BAIRROS, 2 CENTRO)

9) Qual o seu nível de escolaridade?

8 A) Superior Completo (6 ORLA, 1 BAIRROS, 1 CENTRO)

Campo Jurídico|Barreiras (BA)| v.9 |e673| p.01-21 |Janeiro-Junho|2021 
16 B) Médio Completo (4 ORLA, 5 BAIRROS, 7 CENTRO)

6 C) Fundamental Completo (4 BAIRROS, 2 CENTRO)

D) Analfabeto

10) Você sabe para onde devem ser dirigidas as reclamações em caso de má prestação dos serviços de Saneamento Básico em Porto Seguro?

7 A) Governo Federal (4 BAIRROS, 3 CENTRO)

15 B) Governo Estadual (6 ORLA, 4 BAIRROS, 5 CENTRO)

8 C) Governo Municipal (4 ORLA, 2 BAIRROS, 2 CENTRO)

\section{RESULTADOS E DISCUSSÃO}

Conforme a aplicação da metodologia previamente descrita, foram encontradas diferentes percepções dos serviços de saneamento básico prestados no município de Porto Seguro. Inicialmente, faz-se necessário definir o seu conceito, o qual é explanado pela Lei $\mathrm{n}^{\mathrm{o}} 11.445 / 07$, cujos parâmetros estruturais (abastecimento de água, esgotamento sanitário, coleta e manejo de resíduos sólidos e manejo de águas pluviais) são considerados como o mínimo imprescindível para dignidade da população.

Destarte, através das análises dos resultados obtidos com os questionários percebemos que apesar de $\mathbf{9 0 \%}$ dos entrevistados acreditarem que os serviços de saneamento básico são muito importantes e $83 \%$ acreditarem que não são prestados em plena eficácia, apenas $17 \%$ de todos os entrevistados sabe de fato o que é saneamento básico:

Figura 1: Conhecimento sobre o tema.

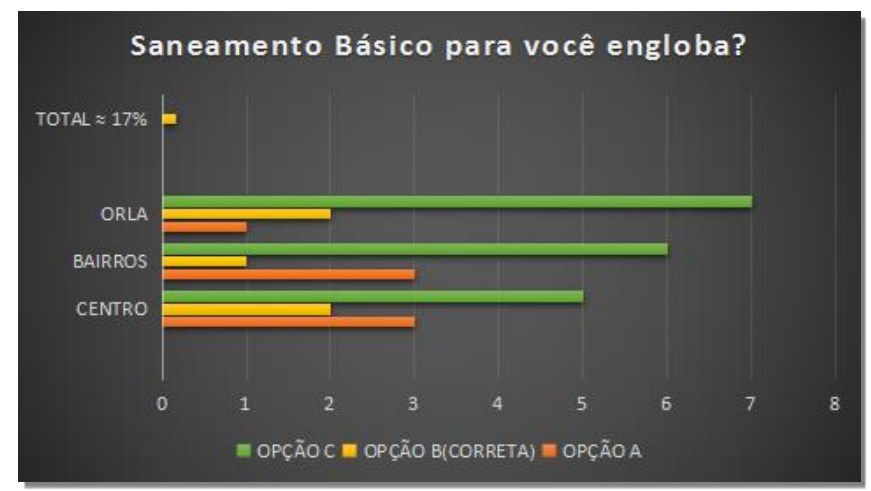

Fonte: Autor.

Campo Jurídico|Barreiras (BA) | v.9 |e673| p.01-21 |Janeiro-Junho|2021 
Figura 2: Eficácia Setorizada.

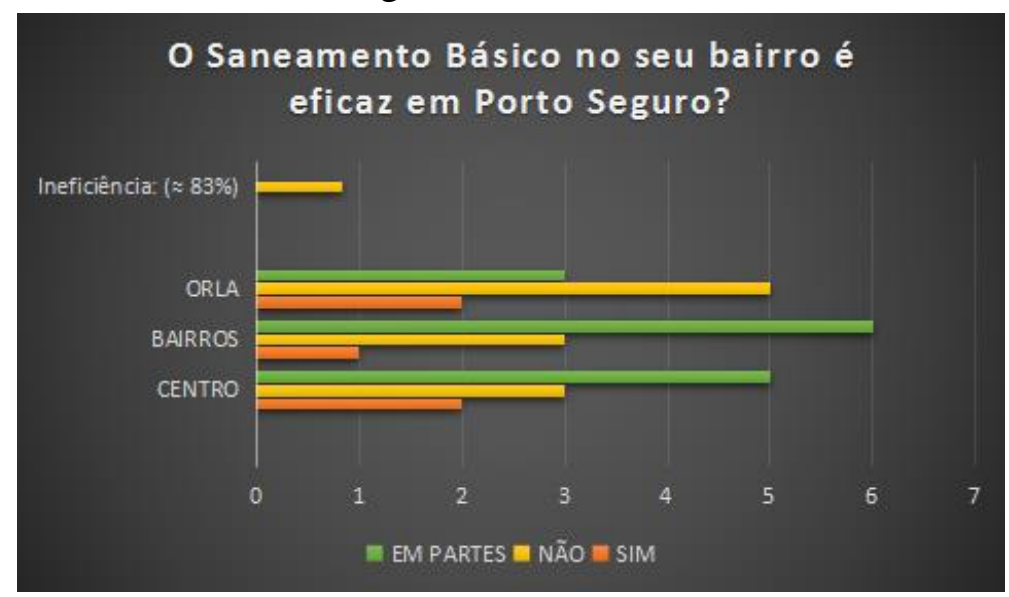

Fonte: Autor.

Assim, fica claro que apesar da grande insatisfação popular, existe também uma grande parcela de desconhecimento da população acerca do tema, dessa forma fica evidente que a participação popular e principalmente a conscientização destes sobre o seu real significado é de suma importância para implementação dos serviços em conformidade com seus anseios. Aguiar, Heller e Melo (2012) dispõem que é no diálogo onde são perscrutados o povo, e que nestes espaços existem as reais possibilidades de expor os seus verdadeiros desejos, trocando assim conhecimentos com o intuito de promover mudanças que realmente sejam as almejadas.

A grande insatisfação dos participantes sobre os serviços prestados acusa a não efetivação de uma estrutura mínima para que prevaleçam os direitos fundamentais, já que:

[...] O direito humano e fundamental ao saneamento básico cumpre papel elementar não apenas para o resguardo do seu próprio âmbito de proteção e conteúdo, mas também para o gozo e o desfrute dos demais direitos humanos (liberais, sociais e ecológicos). Nesse sentido, a relação entre saneamento básico e qualidade de vida resulta evidenciada, pois reflete de forma direta no direito a viver em um ambiente sadio, equilibrado e seguro (SARLET; FENSTERSEIFER, 2011,p. 116-117).

Foram também verificados outros pilares abordados na lei $\mathrm{n}^{\mathrm{o}} 11.445 / 07$ que são relativos à drenagem de águas pluviais e a coleta e manejo de resíduos sólidos. Neste aspecto foi percebido que metade dos participantes verificam constantes alagamentos próximos as suas residências e que em torno de $\mathbf{2 7 \%}$ dos moradores dos bairros não percebem rotineiramente a coleta de lixo, o que pode contribuir para disseminação de 
doenças, já que o despejo inapropriado do lixo serve como fonte de alimento para vetores que causam inúmeras enfermidades.

Diante desses relatos de calamidade, foi averiguado se os moradores estão percebendo melhoras nos serviços ofertados, contudo somente em torno de $\mathbf{7 \%}$ do total de entrevistados acredita que os serviços prestados pela concessionária atual de água e esgoto, a Embasa, são ótimos, sendo que dos participantes que escolheram essa opção todos moram no centro.

Outro aspecto de suma relevância que deve ser ponderado é na percepção de evolução dos serviços prestados, mas apenas $80 \%$ dos participantes acredita que estes não mudaram ou até mesmo pioraram. Diante do exposto, faz-se necessário que os Titulares adequem seus orçamentos na implementação de melhorias "tornando o consumo do patrimônio público compatível com uma política que disponha do erário de modo minimamente razoável” (LEAL; ALVES, 2016, p. 591).

Figura 3: Direcionamento das reclamações.

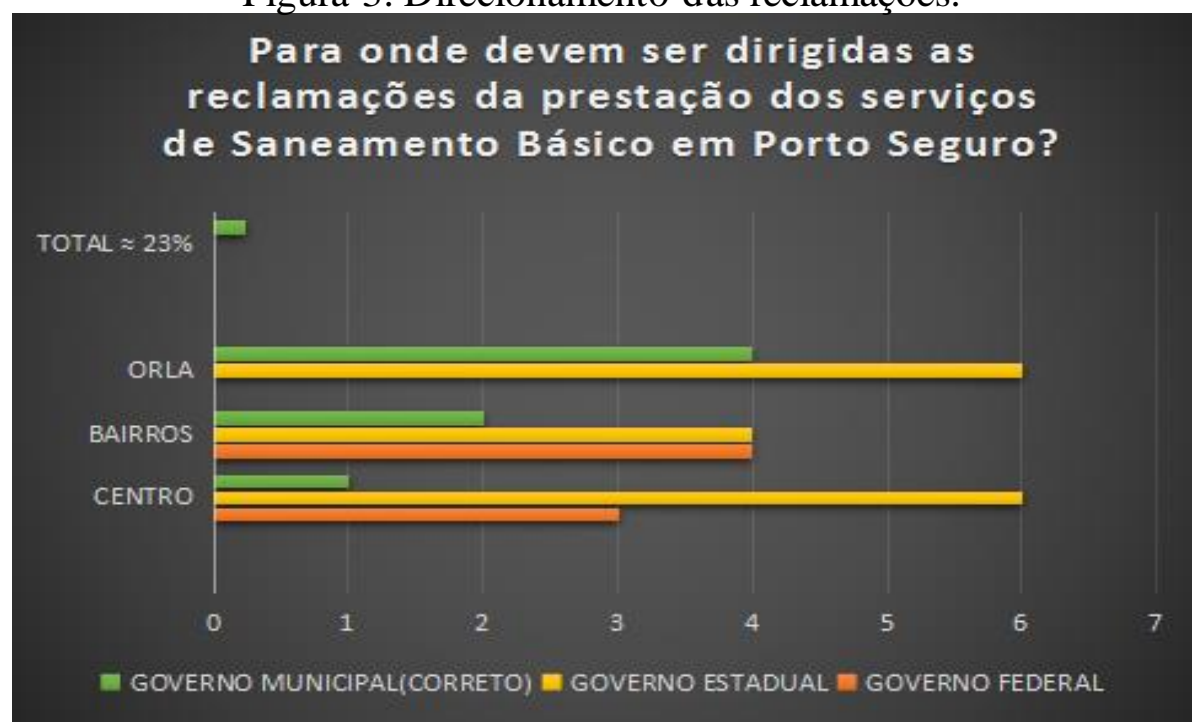

Fonte: Autor.

Diante da análise das respostas dos participantes, foi possível constatar que apenas $23 \%$ sabe que a titularidade para as demandas relativas ao saneamento básica é do Município. Neste sentido, a Lei Federal n 11.445/2007 regulamentada pelo Decreto $\mathrm{n}^{\mathrm{o}} 7.217 / 2010$ estabelece que a responsabilidade pelo planejamento do saneamento básico da população é competência do município, o qual é titular desta prestação de serviços, mesmo essa sendo delegadas às outras empresas públicas ou

Campo Jurídico|Barreiras (BA)| v.9 |e673| p.01-21 |Janeiro-Junho|2021 
privadas. Desta forma, as reclamações sobre os serviços prestados devem ser direcionad as para o titular, neste caso o município de Porto Seguro.

Foi arguido também sobre o nível de escolaridade dos participantes, no intuito de analisar se o público com um melhor nível de escolaridade teria uma percepção diferente acerca dos serviços prestados. No entanto, foi possível verificar que na Orla foi o local em que existiu o maior número de reclamações dos serviços prestados, contrariando até mesmo a hipótese acreditada, pois os bairros periféricos eram estereotipados como os locais de maior descaso do Poder Público. Vale lembrar que o nível de escolaridade dos moradores entrevistados neste local também foi maior do que no centro e nos bairros.

Figura 4: Níveis de escolaridade dos entrevistados.

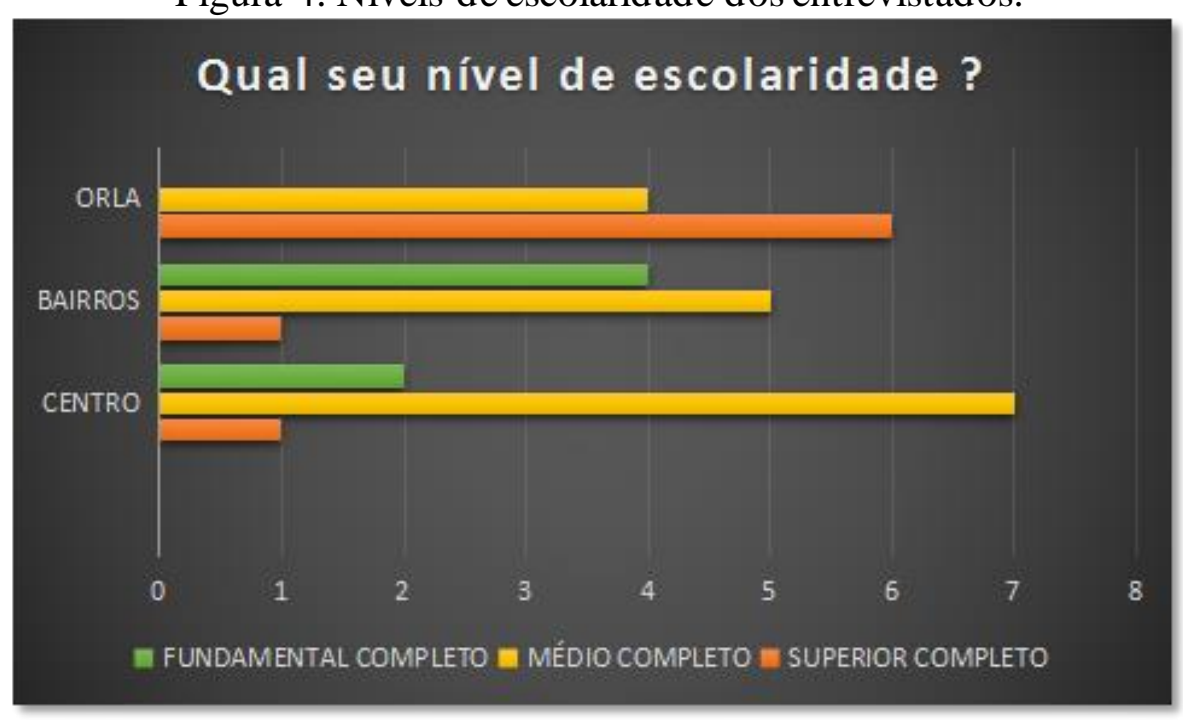

Fonte: Autor.

No entanto na análise dos resultados obtidos foi possível verificar que apesar dos participantes com maior graduação acadêmica, que são os da orla, terem acertado $\mathbf{4 0 \%}$ da pergunta para onde deviam ser enviadas as reclamações, o índice geral ficou em torno de apenas $23 \%$ de acerto. Assim, diante dos resultados apresentad os pode-se inferir que apesar dos bairros periféricos estarem mais longe da rotina dos milhares de turistas que chegam no município, foi na Orla o local onde as pessoas tinham um maior nível acadêmico e concomitantemente tinham as maiores críticas na efetivação deste direito. Contudo, apesar de verificada também a relação entre quanto maior o nível de escolaridade, maior o nível de insatisfação, faz-se necessária a reflexão de que grande parte dos entrevistados não sabia para onde direcionar suas críticas, tampouco sabia o que Campo Jurídico|Barreiras (BA)| v.9 |e673| p.01-21 |Janeiro-Junho|2021 
era saneamento básico, influenciando assim para um distanciamento cada vez maior deste direito fundamental assegurado para todos na Constituição Federal e tornando a participação popular cada vez mais importante para a sua efetiva concretização.

\section{CONSIDERAÇÕES FINAIS}

O presente trabalho teve como intuito colimado estudar a relação entre o que estava disposto na legislação acerca do saneamento básico e o que de fato a população usufruía, com a sua concomitante percepção para com os serviços prestados. Ante os resultados obtidos, ficou evidenciada a enorme insatisfação popular com os serviços de saneamento básico ofertados na cidade de Porto Seguro. Apesar das legislações assegurarem a plena eficácia do serviço, na prática não é o que o povo percebe, já que conforme os resultados obtidos $83 \%$ dos entrevistados não achava que os mesmos eram prestados em plena eficácia.

Outro fator dominante na análise obtida com as entrevistas foi a percepção de que a maior parte não sabia o que de fato englobava os serviços de saneamento básico, tampouco tinham conhecimento para onde dirigirem as suas reclamações e sugestões. No entanto, diferentemente do que foi acreditado inicialmente, não existe uma discrepância no grau de satisfação entre os moradores da orla, centro e dos bairros. Em todos os locais a maioria não se considera amplamente contemplada.

Assim, diante dos fatos apresentados fica claro o relevante papel que a população tem para eficácia dos serviços, pois a mesma é a maior afetada com a errônea ingerência destes recursos públicos. Dessa forma, propõe-se para a efetividade do que está disposto na legislação acerca do saneamento básico, uma conjunta atuação da população de forma consciente para que sejam cobradas as devidas melhorias, tendo assim ciência do real significado do tema e também noção do correto direcionamento ao órgão competente na gestão dos recursos, já que somente assim o saneamento básico pode ser então tratado com a devida importância que o mesmo tem para saúde e qualidade de vida da população, contribuindo assim para incremento do mínimo existencial. 


\section{REFERÊNCIAS}

AGERSA. Relatório de acompanhamento sistema de abastecimento de água e de esgotamento sanitário do município de Porto Seguro. Disponível em:<http://www.agersa.ba.gov.br/wpcontent/uploads/2012/01/relatorio_Porto_Seguro.pdf $>$. Acesso em: 15 de dezembro de 2019.

AGUIAR, M. M; HELLER, L; MELO, E. M. Ação comunicativa na gestão de um serviço privatizado de água e esgotos: uma avaliação em Cachoeiro de Itapemirim (ES). Revista Administração Pública, Rio de Janeiro, v. 46, n. 6, p. 1505-1527, nov/dez. 2012.

ARAUJO, C. P. de. Porto (in) Seguro: A perda do Paraíso: os reflexos do turismo na sua paisagem. Dissertação de Mestrado, USP, Faculdade de Arquitetura e Urbanismo, São Paulo:2004.

BAHIA. Constituição do Estado da Bahia. Salvador, de 2 de agosto de 1947, 2018.Disponível em: <http://www.legislabahia.ba.gov.br/documentos/constituicao-doestado-da-bahia-de-02-de-agosto-de-1947> . Acesso em: 20 de julho de 2019.

BAHIA. Bahia Azul - Programa de Saneamento Ambiental da Bahia. Salvador: Secretaria de Recursos Hídricos, Saneamento e Habitação, 1995.

BRASIL. Constituição da República Federativa do Brasil, de 5 de outubro de 1988, 2016.Disponível em:<http://www.planalto.gov.br/constituicao.htm>. Acesso em: 15 de julho de 2019.

BRASIL. Ministério do Planejamento. Ações de infraestrutura social e urbana. Disponível em: <http://www.pac.gov.br/infraestrutura-social-e-urbana/ubs-unidadebasica-de-saude> Acesso em 25 de setembro de 2019.

BRASIL. Lei $\mathbf{n}^{\mathbf{0}} \mathbf{1 0 . 2 5 7}$, de 10 de julho de 2001: regulamenta os arts. 182 e 183 da Constituição Federal, estabelece diretrizes gerais da política urbana e dá outras providências. Lex: ACQUAVIVA, Marcus Cláudio. Vademecum universitário de direito. 5. ed. rev. ampl. São Paulo: Editora Jurídica Brasileira 2002.

BRASIL. (2007) Lei Federal no 11.445, de 5 de janeiro de 2007. Estabelece Diretrizes nacionais para o saneamento básico. Disponível em:<http://www.planalto.gov.br/ccivil_03/_ato2007-2010/2007/lei/111445.htm>.

Acesso em: 13 de fevereiro de 2020.

CAmArgo, M. L. Psicologia Revista. A Atenção e os Estados de Consciência. Disponível em: $<$ https://www.pucsp.br/clinica/boletimclinico/boletim_02/boletim_02_9\%20.html>Acessado em 17/07/2020.

CHAER, G.; DINIZ, R. R. P.; RIBEIRO, E. A. A técnica do questionário na pesquisa educacional. Evidência, Araxá, v. 7, n. 7, p.251-266, 2011. Anual.

Campo Jurídico|Barreiras (BA) | v.9 |e673| p.01-21 |Janeiro-Junho|2021 
CANELA JUNIOR, O. (2011) O orçamento e a "reserva do possível: dimensionamento no controle judicial de políticas públicas. In: GRINOVER, A.P.; WATANABE, K. (orgs.). O controle jurisdicional de políticas públicas. Rio de Janeiro: Forense. p. 232-233. CHAER, Galdino; DINIZ, Rafael Rosa Pereira; RIBEIRO, Elisa Antônia. A técnica do questionário na pesquisa educacional. Evidência, Araxá, v. 7, n. 7, p.251-266, 2011. Anual.

CUNHA, M. A; BORJA, P.C. O programa de aceleração do crescimento no estado da Bahia e os desafios da universalização do saneamento básico. urbe. Revista Brasileira de Gestão Urbana (Brazilian Journal of Urban Management), 2018, 10(Supl. 1), 173-185. Disponível em: https://www.scielo.br/j/urbe/a/sWWgBWtwG6sQT67qLGTZYNf/?lang=pt\&format=pd f. Acesso em 11 jul 2021.

DATASUS. Tecnologia da Informação a Serviço do SUS. Disponível em: $<$ http://tabnet.datasus.gov.br/cgi/deftohtm.exe?siab/cnv/SIABCbr.def $>$ Acesso em 01 de setembro de 2019.

DEEPASK.O mundo e as cidades através de Gráficos e Mapas. Disponível em: $<$ http://www.deepask.com/goes?page=porto-seguro/BA-Confira-os-indicadores-desaneamento-no-seu-municipio---rede-de-esgoto-fossa-a-ceu-aberto>. Acesso em 06 de setembro de 2019.

EMBASA. Empresa Baiana de Águas e Saneamento. Disponível em: <http://www.embasa.ba.gov.br/ind ex.php/institucional/legislacao-regulacao/leis > . Acesso em: 01 de agosto de 2019.

FOLLADOR, K, PRADO, G. P., PASSOS, M. G., NOTHAFT, S. C. SANEAMENTO BÁSICO: MEIO AMBIENTE E SAÚDE. Disponível em: $\langle$ https://www.mastereditora.com.br/periodico/20150630_220710.pdf $>$ Acesso: 11 jul 2021.

IBGE. Pesquisa Nacional de Amostra a Domicílio 2019. Disponível em:<www.ibge.gov.br/busca.html?searchword=saneamento>. Acesso em: 06 de maio de 2020 .

IBOPE. Pesquisa Trata Brasil "A percepção do brasileiro quanto ao saneamento básico e a responsabilidade do poder público". Disponível em: http://www.tratabrasil.org.br/datafiles/upload s/estudos/pesquisa15/Release-PesquisaIbope-2012.pdf. Acesso em: 15 de março de 2020.

LEAL, M.C.H.; ALVES, F.R.S. (2016) Razoabilidade e teoria da reserva do possível como fundamentos para o controle jurisdicional de políticas públicas: uma análise a partir da teoria do discurso. Espaço Jurídico Journal of Law, Joaçaba, v. 17, n. 2, p. 587-606. Disponível em: <http://doi.org/10.18593/ejjl.v17i2.9255>. Acesso em: 23/03/2020. 
MARCHI, C. M. D. F. Novas perspectivas na gestão do saneamento: apresentação de um modelo de destinação final de resíduos sólidos urbanos. URBE. Revista Brasileira de Gestão Urbana, v. 7, n. 1, p. 91-105, jan. /abr. 2015.

MINAYO, M. C. de S.. Ciência, Técnica e Arte: o desafio da pesquisa social. In: MINAYO, Maria Cecília de S. (Org.). Pesquisa Social: teoria, método e criatividade. $8^{\text {a }}$ edição. Petrópolis: Vozes, 1998. NIELSEN, J; MACK, R.L. Métodos de inspeção de usabilidade. Nova Iorque: John Wiley \& Sons, 2004.

MINAYO, M. C. S. Cientificidade, generalização e divulgação de estudos qualitativos. Ciência \& Saúde Coletiva. Rio de Janeiro, v. 22, n. 1, p. 16. 17, 2017.

NIELSEN, J; MACK, R.L. Métodos de inspeção de usabilidade. Nova Iorque: John Wiley \& Sons, 2004.

PORTO SEGURO. Prefeitura Municipal. Plano Municipal de Saneamento Básico. Disponível em: $<$ http://portoseguro.ba.gov.br/ppp/storage/files/plano-municipal-desaneamento-basico.pdf $>$ Acesso em 10 de setembro de 2019.

PORTO SEGURO. Prefeitura Municipal. Relação das Unidades de Saúde da Família. Disponível em:<http://portoseguro.ba.gov.br/novo/secretarias-e-orgaos/>Acessado em 27 de abril de 2020.

PEMAPES. Plano Estadual de manejo de águas pluviais e esgotamento sanitário. Porto Seguro, 2011. Estudo de áreas críticas quanto a risco de enchentes e proposição de soluções. Disponível em: <http://www.sihs.ba.gov.br/arquivos/File/RDS24CostadoDescoBrimentoPortoSeguro.pdf $>$. Acesso em: 12 de janeiro de 2020.

SARLET, I. W.; FENSTERSEIFER, T. Direito Constitucional Ambiental: estudos sobre a Constituição, os Direitos Fundamentais e a proteção do ambiente. São Paulo: Revista dos Tribunais 2011.Disponível em <http://www.scielo.br/scielo.php?pid=S14131522019000300493\&script=sci_arttext $>$. Acesso em: 22 de março de 2020.

SOARES, A. F. S.; NUNES, B. C. R.; SANTOS, C. V.; COSTA, F. C. R.; SANTOS, H. R.; SILVA, L. F. M.; SOUZA, R. M. G. R. Recomendações para prevenção do contágio da COVID-19 (novo coronavírus -(SARS-CoV-2) pela água e por esgoto doméstico. [Brasil]: Sala Técnica de Saneamento, 2020. Disponível em: http://tratabrasil.org.br/covid 19/assets/pdf/cartilha_covid-19.pdf. Acesso em: 11 jul. 2021.

VARELlA, A. D.. Importância da água para o ser humano. Disponível em :<https://drauziovarella.uol.com.br/alimentacao/cinco-motivos-para-nao-deixar-detomar-agua/>Acessado em 28 de abril de 2020.

Campo Jurídico|Barreiras (BA) | v.9 |e673| p.01-21 |Janeiro-Junho|2021 